\title{
Factors Associated with Under Corrected Refractive Errors in an Older Population.
}

\author{
Madhavi Chevuturu ${ }^{1}$ \\ ${ }_{1}$ Professor, Department of Ophthalmology, Mediciti Institute of Medical Sciences, Ghanpur, Medchal, Ranga Reddy, Telangana, India.
}

\section{Abstract}

Background: Recent studies have shown severe impact of visual impairment in elderly population in the form of falls, fractures, poor mobility, general health, morbidity and mortality. Visual acuity can be improved by correcting the refractive errors. Therefore, the present study was designed to study the demographic and visual acuity related factors associated with undercorrected refractive error. Subjects and Methods: The present study included 1236 randomly selected subjects of 50 years and above age group. Among them 1000 subjects were included in the study. Logarithm of the minimum angle of resolution chart was used for measuring visual activity. The chart was read at 8 feet and retro illuminated with automatic calibration to $85 \mathrm{~cd} / \mathrm{m}^{2}$. Initially visual acuity was assessed with the subject's current glasses, if worn .Then using a Humphrey 530 Automatic Refractor an objective refraction was performed on all participants. Results: Among all the study participants 230 patients showed visual acuity <45 letters (6/9 or worse) while there were 110 participants with under corrected refractive error (using the two line criterion). Hyperopia was very common among undercorrected refractive error subjects with $\mathrm{p}$ value $<0.05$. In contrast, no association was found between undercorrected refractive error and myopia ( $>0.05$ ). Time duration since last examination was directly relation between incidence of undercorrected refractive error in our study population with $\mathrm{p}$ value $>0.05$. Subjects who stated that they had worn distance glasses in the past were less likely to have undercorrected refractive error (OR 0.20 ; $95 \%$ CI 0.19 to $0.38 ; \mathrm{p}>0.05$ ). Conclusion: Findings of the present study demonstrated that prevalence of undercorrected refractive error is high in elderly population. Further, results of our study showed that aging, hyperopia, socioeconomic status and isolation were directly related to the undercorrected refractive error in elderly population. These undercorrected refractive errors can be corrected to some extent by using distance glasses in elderly population. These findings of our study might be helpful for the ophthalmologist recognising the risk factors and their consequences on visual acuity of elderly population.

Keywords: Refractory error, Elderly, Aging, Risk factors.

Corresponding Author: Dr. Madhavi Chevuturu, Professor, Department of Ophthalmology, Mediciti Institute of Medical Sciences, Ghanpur, Medchal, Ranga Reddy, Telangana, India.

Received: September 2018

Accepted: September 2018

\section{Introduction}

Recent studies have shown severe impact of visual impairment in elderly population in the form of falls, fractures, poor mobility, general health, morbidity and mortality. It can even produce hindrance in independent living of older people and use of various community support services. ${ }^{[1-13]}$ The effects of these refractive errors has been found most severe for irreversible refractive error. Reports are there which show the fatal effects of undercorrected refractive error which can even lead to death. ${ }^{[13,14]}$

Various studies have recorded comparatively high prevalence of undercorrected refractive errors and their associated factors in elderly population. ${ }^{[15]}$ Researchers have shown that there was improvement of at least one line on snellen chart by refraction more than $50 \%$ of study population. ${ }^{[16]}$ An improvement of visual acuity can be attenuate even subjects with visual acuity of $6 / 6$ minus two letters. ${ }^{[17]}$ There are a huge number of population is living with undercorrected refractive error. Their visual acuity can be improved by correcting the refractive errors. ${ }^{[18]}$ Therefore, the present study was designed to study the demographic and visual acuity related factors associated with undercorrected refractive error.

\section{Subjects and Methods}

The Eye Disease Survey is a hospital based survey of common eye diseases in a population aged 50 years and older coming to Mediciti College of Medical Sciences, Hyderabad. The present study included 1236 randomly selected subjects of 50 years and above age group. Among them 1000 subjects were included in the study. The examination included an interviewer managed questionnaire and a complete eye examination.

Subjects were asked to rate their overall health status as excellent, good, fair, or poor. Details were asked about if they are having any diseases including cancer, diabetes, arthritis, ischaemic heart disease, and hypertension. Level 
of dependence on others was evaluated by asking participants if they were able to go out alone, to town, to visit friends or to shop and whether they lived alone or used community support services.

Logarithm of the minimum angle of resolution chart was used for measuring visual activity. The chart was read at 8 feet and retro illuminated with automatic calibration to 85 $\mathrm{cd} / \mathrm{m} 2$. Initially visual acuity was assessed with the subject's current glasses, if worn. Then using a Humphrey 530 Automatic Refractor an objective refraction was performed on all participants. The auto refractor correction was located in a trial lens frame and a subjective refraction was performed using the Beaver Dam Eye Study modification of the Early Treatment Diabetic Retinopathy, for all subjects with a presenting visual acuity of $<54$ letters read correctly. (6/6 Snellen equivalent) Study protocol. ${ }^{[19]}$ In $0.25 \mathrm{D}$ steps, refractive error was tested. Both $0.25 \mathrm{D}$ and 0.5D Jackson Cross cylinders were used to test cylinder power, which was recorded in the negative form. For each eye, best corrected visual acuity was recorded as the number of letters read, following refraction, from $0-70.20$ Slit lamp and retro illumination lens photographs were taken to establish the presence of cataract, and marked as described previously. ${ }^{[21,22]}$ At examination history of past cataract surgery was confirmed. From stereoscopic retinal photographs presence of late stage age related maculopathy was assessed. ${ }^{[23]}$ Open angle glaucoma was diagnosed by the presence of matching typical glaucomatous visual field loss on automated perimetry and optic disc cupping with rim thinning, as described. ${ }^{[2]}$ Details were taken from participants about their eye status, when they had last seen an optometrist or ophthalmologist, and whether they had ever worn glasses to see clearly in the distance and whether they had noticed a change in their vision.

The spherical equivalent refraction used the formula (sphere + cylinder/2). Hyperopia was defined as SER > +1.00 dioptres and myopia as SER <-1.00 dioptres. We classified corrected visual acuity into three groups, based on the number of letters read correctly after refraction: 54-70 letters, 41-53 letters, and < 41 letters. We defined clinically relevant under corrected refractive error as an improvement of $>10$ letters (two lines on the log- MAR chart), after refraction in subjects with a presenting visual acuity $<45$ letters (6/9 Snellen equivalent). For analysis the eye with the better presenting visual insight was selected for each participant. This definition of under corrected refractive error was chosen as it represents a clinically relevant level.

A second criterion defining a more severe level of correctable refractive error was an improvement of 15 or more letters in subjects with presenting visual acuity less than 40 letters.

Statistical analysis

Logistic regression analysis was performed using the SPSS. Age-sex adjusted, and multivariate analyses were performed. $\mathrm{p}$ Values $<0.05$ were taken to indicate statistical significance. Mantel-Haenzsel tests for trend were calculated to assess the effects of age and time since eye examination. For vision and eye disease variables, values for the eye with the better presenting visual acuity were used in analyses.

\section{Results}

Out of total 1236 subjects, 1000 participants between 50 to 80 years age group were included in the present study. Study participants included $560(56 \%)$ male subjects with mean age $65.2 \pm 9.8$ years and 440 female subjects (44\%) with mean age $63.8 \pm 10.4$ years.

Among all the study participants 230 patients showed visual acuity $<45$ letters $(6 / 9$ or worse) while there were 110 participants with under corrected refractive error (using the two line criterion). Further, 450 patients had visual acuity was $<40$ letters which was improved by three or more lines with refraction.

Table 1: Shows the prevalence of different levels of undercorrected refractive error.

\begin{tabular}{|l|l|l|}
\hline $\begin{array}{l}\text { Number of lines } \\
\text { improved }\end{array}$ & $\begin{array}{l}\text { Number of subjects } \\
\text { with undercorrected } \\
\text { refractive error }\end{array}$ & $\begin{array}{l}\text { Percentage of total } \\
\text { patients }\end{array}$ \\
\hline$\geq 1$ line & 230 & $23 \%$ \\
\hline$\geq 2$ lines & 110 & $11 \%$ \\
\hline$\geq 3$ lines & 45 & $4.5 \%$ \\
\hline$\geq 4$ lines & 21 & $2.1 \%$ \\
\hline
\end{tabular}

[Table 2] shows that there was no significant difference between the refractive error between male and female $(p>0.05)$. Further, there was a significant increase of undercorrected refractive error with increase of age. There was a significant difference between the rural and urban population in undercorrected refractive error prevalence. However, undercorrected refractive error was high in illiterate population compare to literate population; but $\mathrm{p}$ value was insignificant. There was no relation of undercorrected refractive error with general health of our study population. Undercorrected refractive error was more common among subjects who live alone.

Table 2: shows associations among demographic, social, general and medical health factors with undercorrected refractive error, after adjusting for age and sex.

\begin{tabular}{|c|c|c|c|c|}
\hline Variable & $\begin{array}{l}\text { Number with } \\
\text { presenting VA }<6 / 9\end{array}$ & $>2$ line improvement $(\%)$ & OR $(95 \%$ CI $)$ & p value \\
\hline $\begin{array}{l}\text { Sex } \\
\text { Males } \\
\text { Females }\end{array}$ & $\begin{array}{l}50 \\
60\end{array}$ & $\begin{array}{l}45.5 \% \\
54.5 \%\end{array}$ & $\begin{array}{l}1.00 \text { (reference) } \\
1.14(0.91 \text { to } 1.41)\end{array}$ & $>0.05$ \\
\hline $\begin{array}{l}\text { Age groups (Years) } \\
50 \text { to } 59 \\
60 \text { to } 69 \\
70 \text { to } 79\end{array}$ & $\begin{array}{l}17 \\
35 \\
37\end{array}$ & $\begin{array}{l}15.45 \% \\
31.81 \% \\
33.63 \%\end{array}$ & $\begin{array}{l}1.00 \text { (reference) } \\
3.43(2.33 \text { to } 5.06) \\
1.85(1.34 \text { to } 2.56)\end{array}$ & $\begin{array}{l}<0.05 \\
<0.05\end{array}$ \\
\hline
\end{tabular}




\begin{tabular}{|c|c|c|c|c|}
\hline$\leq 80$ & 21 & $19.09 \%$ & 2.67 (1.92 to 3.70$)$ & $<0.05$ \\
\hline $\begin{array}{l}\text { Place } \\
\text { Rural } \\
\text { Urban }\end{array}$ & $\begin{array}{l}60 \\
50\end{array}$ & $\begin{array}{l}54.5 \% \\
44.5 \%\end{array}$ & $\begin{array}{l}1.00 \text { (reference) } \\
1.14(1.22 \text { to } 1.98)\end{array}$ & $>0.05$ \\
\hline $\begin{array}{l}\text { Education } \\
\text { Illiterate } \\
\text { Literate }\end{array}$ & $\begin{array}{l}60 \\
50\end{array}$ & $\begin{array}{l}54.5 \% \\
45.5 \%\end{array}$ & $\begin{array}{l}1.23(0.49 \text { to } 0.92) \\
1.25(0.58 \text { to } 1.06)\end{array}$ & $<0.05$ \\
\hline $\begin{array}{l}\text { Self rated health } \\
\text { Excellent } \\
\text { Good } \\
\text { Fair } \\
\text { Poor }\end{array}$ & $\begin{array}{l}20 \\
60 \\
23 \\
7 \\
\end{array}$ & $\begin{array}{l}18.18 \% \\
54.5 \% \\
20.09 \% \\
6.36 \% \\
\end{array}$ & $\begin{array}{l}1.00 \text { (reference) } \\
1.23 \text { (0.89 to } 1.63) \\
1.25(0.92 \text { to } 1.68) \\
1.17(0.87 \text { to } 1.58)\end{array}$ & $\begin{array}{l}>0.05 \\
>0.05 \\
>0.05\end{array}$ \\
\hline Living alone & 22 & $20 \%$ & $1.15(0.52$ to 1.06$)$ & $<0.05$ \\
\hline
\end{tabular}

Table 3: Age and sex adjusted associations with ocular factors

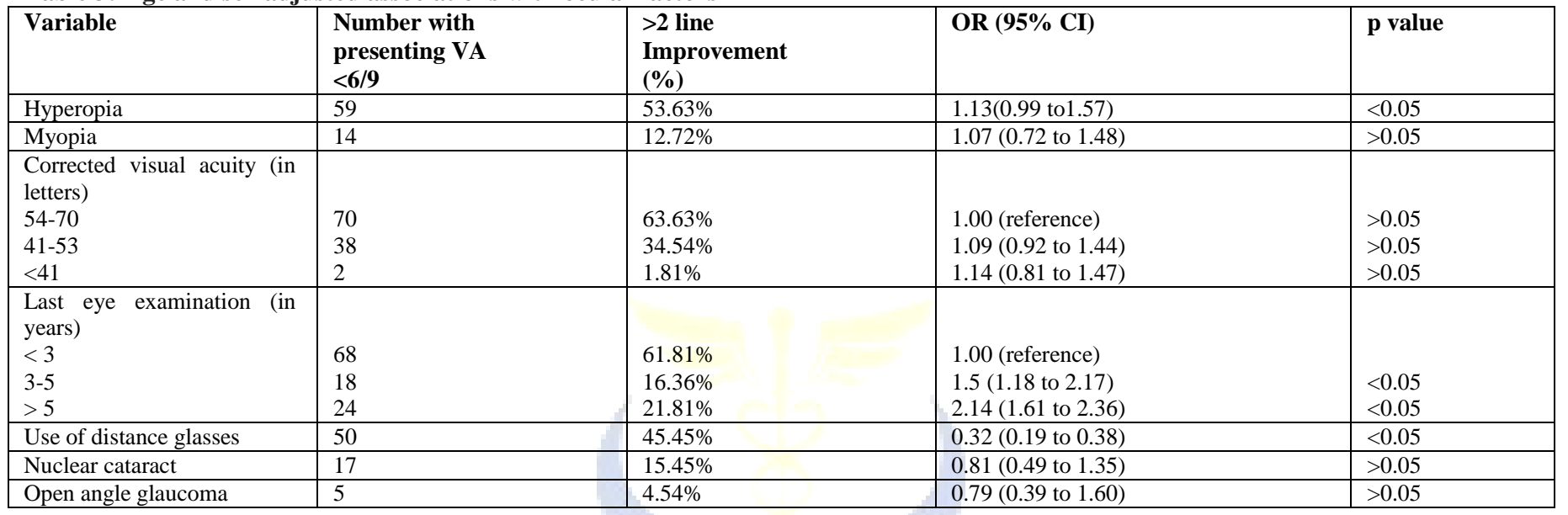

There was no significant relation of undercorrected refractive error with gender. Further, results revealed that undercorrected refractive error were more prevalent depend up on advance age, duration of last eye examination, solitude living, hyperopia. Hyperopia was very common among undercorrected refractive error subjects with $\mathrm{p}$ value $<0.05$. In contrast, no association was found between undercorrected refractive error and myopia $(p>0.05)$. Time duration since last examination was directly relation between incidence of undercorrected refractive error in our study population with $\mathrm{p}$ value $>0.05$. Subjects who stated that they had worn distance glasses in the past were less likely to have undercorrected refractive error (OR 0.20; 95\% CI 0.19 to $0.38 ; p>0.05$ ). [Table 3]

\section{Discussion}

Findings of the current study showed that undercorrected refractive errors were more common in elderly population. Moreover, one fourth of these elderly population recorded improved visual acuity at least one line after removing the refractive errors. Further, it was recorded in the present study that all most half of the study population with visual acuity of $6 / 9$ or less improved their visual acuity to $6 / 6$ or up to two lines at least.

Further, our findings suggest that there was a strong relation between increase of age and undercorrected refractive error in present study population. There was an increase of $51 \%$ in undercorrected refractive error by each enhancement of 10 years. These findings are supported by the previous studies of Liou HL at al, ${ }^{[17]}$ and Attebo $\mathrm{K}$ et al, ${ }^{[20]}$ as they recorded increase incidence of undercorrected refractive error with increase of age. Similarly, Harwood RH et al 5 observed increase incidence of undercorrected refractive error with aging in their study population.

There was an insignificant relation between general health and illness with undercorrected refractive error. Hyperopic refraction was found linked with increase of age resulted in undercorrected refractive error in our study.

Various studies have recorded that hyperopic refractive shift occurred with advance age which further leads to increase incidence of refractory errors. ${ }^{[25-27]}$

Present study showed that use of distance glasses was inversely associated with undercorrected refractive error; whereas, subjective perception of poor vision was also not related to the same. These findings are consistent with the findings of previous studies of Liou HL at al, ${ }^{[17]}$ and Salive $\mathrm{M}$ et $\mathrm{al},{ }^{[13]}$ as they recorded subjects using glasses were less prone to undercorrected refractive error.

Further, it was recorded in our study that undercorrected refractive error was improved by using distance glasses distance glasses. These findings are very similar to the earlier study of Liou HL at $\mathrm{al}^{[17]}$ as they showed a significant improvement in undercorrected refractive error by using distance glasses in their study population.

This seems to be as lot of elderly subjects with increased hyperopia most of the time are unaware that use of distance glasses can improve their vision. They had not gone to use the distance glasses due to various reasons including 
unawareness, contended with their visual acuity and unwillingness to use distance glasses. ${ }^{[19,20,23]}$

There was a significant relation between socioeconomic status and undercorrected refractive. These findings are supported by the findings of earlier study of Mitchell P et al. ${ }^{[21]}$ This increase prevalence of undercorrected refractive error in lower socioeconomic group might be lack of timely correction of refractive errors due to cost of attending an ophthalmologist. ${ }^{[18]}$

Prevalence of undercorrected refractive error was more in subjects living alone and subjects who was not going to ophthalmologist seeking his advice regularly. These results are in agreement with earlier studies of Liou HL et al, ${ }^{[17]}$ and Attebo K et al, ${ }^{[20]}$ as they observed increased prevalence of undercorrected refractive error in subjects who did not go for regular eye examination and lived all alone.

Present study recorded that 6 subjects with visual acuity worse than $6 / 12$ after correction of refractive error were still driving the vehicle which can be a cause of future road accident as various reports suggest that impairment visual field is among the important causes of automobile accidents. ${ }^{[28,29]}$ However, it is important to maintain the visual acuity of elderly population to sustain their driving ability and independence. ${ }^{[30]}$

Current study recorded $10 \%$ prevalence of undercorrected refractive error in study population. These findings are supported by the findings of the earlier study Liou HL at al, ${ }^{[17]}$ as they recorded similar rate of undercorrected refractive error in their study population. Findings of both studies were relatively similar; in spite of various differences between our study and study of Liou HL at al. ${ }^{[17]}$

These findings seek the attention for the importance of regular examination of eyes in elderly subjects as undercorrected refractory error is very common in older people in previous studies. ${ }^{[17,21]}$

\section{Conclusion}

Findings of the present study demonstrated that prevalence of undercorrected refractive error is high in elderly population. Further, results of our study showed that aging, hyperopia, socioeconomic status and isolation were directly related to the undercorrected refractive error in elderly population. A large number of our study population was still driving vehicles besides having correctable visual acuity worse than 6/12. However, these undercorrected refractive errors can be corrected to some extent by using distance glasses in elderly population. These findings of our study might be helpful for the ophthalmologist recognising the risk factors and their consequences on visual acuity of elderly population.

\section{References}

1. Wang JJ, Mitchell P, Smith W, et al. Factors associated with use community support services in an older Australian Population. Aust N Z J Ophthalmol 1999;23:147-53.

2. Ivers RQ, Norton R, Cumming RG, et al. Visual impairment and risk of hip fracture. Am J Epidemiol 2000;152:633-9.

3. Wang JJ, Mitchell P, Simpson J, et al. Visual impairment, age-related cataract, and mortality. Arch Ophthalmol 2001;119:1186-90.

4. McCarty CA, Nanjan MB, Taylor HR. Vision impairment predicts 5 year mortality. Br J Ophthalmol 2001;85:322-6.

5. Harwood RH. Visual problems and falls. Age Ageing 2001;30(Suppl 4):13-18.

6. Jorm AF, Henderson AS, Scott R, et al. Factors associated with the wish to die in elderly people. Age Ageing 1995;24:389-92.

7. Grisso JA, Kelsey JL, Strom BL, et al. Risk factors for falls as a cause of hip fracture in women. The Northeast Hip Fracture Study Group. N Engl J Med 1991;324:1326-31.

8. Myers AH, Young Y, Langlois JA. Prevention of falls in the elderly. Bone 1996;18(Suppl 1):87S-101S.

9. Felson DT, Anderson JJ, Hannan MT, et al. Impaired vision and hip fracture. The Framingham Study. J Am Geriatr Soc 1989;37:495500.

10. Dargent-Molina P, Favier F, Grandjean H, et al. Fall-related factors and risk of hip fracture: the EPIDOS prospective study. Lancet 1996;348:145-9.

11. Stuck AE, Walthert JM, Nikolaus T, et al. Risk factors for functional status decline in community-living elderly people: a systematic literature review. Soc Sci Med 1999;48:445-69.

12. Sarkisian CA, Liu H, Gutierrez PR, et al. Modifiable risk factors predict functional decline among older women: a prospectively validated clinical prediction tool. The Study of Osteoporotic Fractures Research Group. J Am Geriatr Soc 2000;48:170-8.

13. Salive M, Guranik J, Christen W, et al. Functional blindness and visual impairment in older adults from three communities. Ophthalmology 1992;99:1840-7. 1044 Thiagalingam, Cumming, Mitchell.

14. Klein BE, Klein R, Lee KE, et al. Performance-based and selfassessed measures of visual function as related to history of falls, hip fractures, and measured gait time. The Beaver Dam Eye Study. Ophthalmology 1998;105:160-4.

15. $\mathrm{Li} \mathrm{S}, \mathrm{Xu} \mathrm{J}, \mathrm{He} \mathrm{M}$, et al. A survey of blindness and cataract surgery in Doumen County, China. Ophthalmology 1999;106:1602-8.

16. Tielsch J, Sommer A, Witt K, et al. Bindness and visual impairment in an American Urban Population. Arch Ophthalmol 1990;108:28690.

17. Liou HL, McCarty CA, Jin CL, et al. Prevalence and predictors of undercorrected refractive errors in the Victorian population. Am J Ophthalmol 1999;127:590-6.

18. Attebo K, Mitchell P, Smith W. Visual acuity and the causes of visual loss in Australia. Ophthalmology 1996;103:357-64.

19. Klein R, Klein B. Beaver Dam Eye Study. Manual of operations. Springfield, VA: National Technical Information Service, US Department of Commerce, 1991.

20. Attebo K, Ivers RQ, Mitchell P. Refractive errors in an older population: the Blue Mountains Eye Study. Ophthalmology 1999;106:1066-72.

21. Mitchell P, Cumming RG, Attebo K, et al. Prevalence of cataract in Australia: the Blue Mountains Eye Study. Ophthalmology 1997:104:581-8.

22. Panchapakesan J, Cumming RG, Mitchell P. Reproducibility of the Wisconsin cataract grading system in the Blue Mountains Eye Study. Ophthalmic Epidemiol 1997;4:119-26.

23. Wang JJ, Mitchell PG, Cumming RG, et al. Cataract and age-related maculopathy: the Blue Mountains Eye Study. Ophthalmic Epidemiol 1999;6:317-26.

24. Mitchell P, Hourihan F, Sandbach J, et al. The relationship between glaucoma and myopia: the Blue Mountains Eye Study [see comments]. Ophthalmology 1999;106:2010-5.

25. Hyams S, Pokotilo E, Shkurko G. Prevalence of refractive errors in adults over 40: a survey of 8102 eyes. Br J Ophthalmol 1977;61:42832.

26. Wensor M, McCarty CA, Taylor HR. Prevalence and risk factors of myopia in Victoria, Australia. Arch Ophthalmol 1999;117:658-63.

27. Wang Q, Klein B, Klein R, et al. Refractive status in the Beaver Dam Eye Study. Invest Ophthalmol Vis Sci 1994;35:4344-7.

28. Owsley C, McGwin G Jr, Ball K. Vision impairment, eye disease, and injurious motor vehicle crashes in the elderly. Ophthalmic Epidemiol 1998;5:101-13. 


\section{Cheruturu ; Under Carrected Refractive Errars in an Older Papulation}

29. Wood JM, Troutbeck R. Effect of visual impairment on driving. Hum

1998;23:48-52.

Factors 1994;36:476-87.

30. Wilkinson ME. Driving with a visual impairment. Insight

Copyright: (C) the author(s), 2019. It is an open-access article distributed under the terms of the Creative Commons Attribution License (CC BY 4.0), which permits authors to retain ownership of the copyright for their content, and allow anyone to download, reuse, reprint, modify, distribute and/or copy the content as long as the original authors and source are cited.

How to cite this article: Chevuturu M. Factors Associated with Under Corrected Refractive Errors in an Older Population. Asian J. Med. Res. 2019;8(1):OT15-OT19.

DOI: dx.doi.org/10.21276/ajmr.2019.8.1.OT5 